\title{
Promotion of Inclusive Tourism by National Destination Management Organizations
}

\author{
Paulo Rita \\ NOVA Information Management School (NOVA IMS), Universidade NOVA de Lisboa, Portugal \\ (corresponding author: prita@novaims.unl.pt) \\ Nuno António \\ NOVA Information Management School (NOVA IMS), Universidade NOVA de Lisboa, Portugal
}

This is the author accepted manuscript version of the article published by Elsevier as:

Rita, P., \& António, N. (2020). Promotion of inclusive tourism by national destination management organizations. Worldwide Hospitality and Tourism Themes. [Advanced online publication on 3 december 2020]. https://doi.org/10.1108/WHATT-07-2020-0068

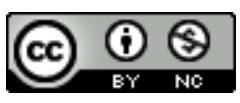

This work is licensed under a Creative Commons Attribution-NonCommercial 4.0 International License. 


\section{Promotion of Inclusive Tourism by \\ National Destination Management Organizations}

Paulo Rita - NOVA Information Management School (NOVA IMS), Universidade NOVA de Lisboa, Portugal (corresponding author: prita@novaims.unl.pt)

Nuno António - NOVA Information Management School (NOVA IMS), Universidade NOVA de Lisboa, Portugal

\section{Abstract}

- Purpose: Inclusive tourism has the potential to counterweight disadvantages brought up by tourism development and effectively exerting positive impacts on society at large and specifically in tourist destinations. However, there is a research gap in studies on inclusiveness related to the promotional efforts of national Destination Management Organizations.

- Design: Data Science-based methods, mainly Text Mining and Image Mining, were employed to analyze both the explicit and implicit content in text and images in the English brochures published by nine European official Destination Management Organizations.

- Findings: Results highlighted that the countries' attitudes towards inclusion were aligned with what the countries' Destination Management Organizations were promoting, especially in the case of highly ranked countries in inclusiveness index. However, there were differences between their explicit content (what they write in text) and their implicit content (what they show in images).

- Originality: The combined analysis of text and image content allowed for a complete understanding on how national's Destination Management Organizations are promoting inclusion, showing that Destination Management Organizations should make an effort in improving their promotional material, above all in the images.

Keywords: Inclusive Tourism; Destination Management Organizations; Marketing; Promotion; Data Science; Text Mining; Image Mining. 


\section{Introduction}

For the last few decades tourism has grown significantly across the world showing rates outpacing the economy; for example, 2019 brought another year of strong growth in international arrivals ( $+4 \%$ to reach 1.5 billion), although slower when compared to the achieved rates of 2017 and 2018 ( $+6 \%$ in each year) (WNTO, 2020). However, tourism influence has not been only positive on economic and social dimensions; indeed, this sector has also been the subject of criticism for causing negative impacts on the environment and contributing to both and economic and social inequality (e.g., Garau-Vadell et al., 2018; Muler Gonzalez et al., 2018).

Following the Sustainable Development Goals (SDG) set by the United Nations Development Program (UNDP, 2015), inclusive tourism has been recently defined as "transformative tourism in which marginalized groups are engaged in ethical production or consumption of tourism and the sharing of its benefits" (Scheyvens \& Biddulph, 2018). This approach has the potential to counterweight disadvantages brought up by tourism development and effectively exerting positive impacts on society at large and specifically in tourist destinations.

In travel, destinations are represented by Destination Management Organizations (DMOs) which have the responsibility to be engaged in the development of their respective long-term tourism marketing strategy. These are generally non-for-profit organizations in charge of promoting destination attractions, accommodation, restaurants, events, transportation, tourism services to generating markets. Destination marketing has been addressed by researchers from different perspectives such as collaborative marketing (Garrod \& Fyall, 2017), use of technologies (Marasco et al., 2018), local cuisine (Okumus et al., 2018). Notwithstanding, there is a research gap in studies on inclusiveness related with the promotional efforts of DMO, notably at the national level. Thus, the following research question was formulated to guide the current study:

RQ: Does the promotion material from the National Destination Management Organizations reflect the country's level of inclusion?

This paper continues with the review of the relevant scientific literature, providing information on the data and methods used, namely emphasizing both text and image mining, reporting on the 
achieved results as well as bringing them to discussion vis-à-vis other studies, and concluding with main research contributions, managerial implications, study limitations and recommendations for future research.

\section{Literature Review}

Inclusion is often used as an opposite concept to discrimination (Collins, 2003). Whereas inclusion gives everyone the opportunity to be full members of society, discrimination is based on unfair judgement and treatment of minorities, excluding people from social and economic activities due to some defining features like ethnicity, religion or gender. Hence, fighting for inclusion is the way to undermine the chances for discrimination to occur since it pulls everybody together in respecting values, beliefs and preferences of others.

Bakker (2019) developed a conceptual framework for identifying and prioritizing the constraints to tourism-driven inclusive growth by means of linking the discussion on inclusive growth to the specific features of the tourism industry. This study identified three elements contributing to the tourism sector's capability to contribute to an inclusive growth strategy: growth of tourism opportunities; equal access to tourism opportunities; and equal outcome of tourism opportunities.

Fostering inclusive tourism enables to bring into this sector those who are more frequently marginalized or sometimes even excluded from tourism. The implementation of this perspective drives direct benefits to those involved (Biddulph \& Scheyvens, 2018). Research in inclusive tourism has addressed several dimensions such as race and ethnicity, gender, sexual orientation, age, religion, income inequality, and political representation.

Previous tourism studies identified differences in race as one of the leading explanations for inequality of access to tourism opportunities (Scheyvens, 2002). Many aspects of tourism are permeated by ethnicity which in many cases is involved with a complex interrelation with the social structure. Not only tourist destinations have been using strategies to cope with stereotyping, but tourism has also contributed to identity formation in countries, and majority populations have been encouraged to re-evaluate their perceptions about minorities (Hitchcock, 
1999).

Moreover, tourism influences the re-interpretation of identity among members of local communities who depend on or are affected by this sector and its many businesses. According to Jamison (1999), tourism development mitigated the inter-ethnic relationships within a community in Kenya. Another interesting study was conducted by Krymkowski et al. (2014), who took into account that members of racial/ethnic minority groups tend to visit national parks at lower rates than whites, and recommended the design of park and outdoor recreation opportunities in articulation with the values of minority racial/ethnic groups.

A bibliometric analysis of 466 journal papers published during 1985-2012 on tourism gender research was presented by Figueroa-Domecq et al. (2015) in a thorough critical analysis of this sub-field of tourism. After categorizing prevailing themes and methodologies as well as identifying the most productive researchers and popular scientific journal, these authors concluded that tourism gender research remains marginal to tourism enquiry, lacking the critical mass of research leaders, publications, citations and multi-institutional networks characterizing other tourism sub-fields. An interesting study was developed by Duffy et al. (2015) who explored the ways in which employing women in the tourism sector challenged or reinforced the traditional gender ideology in the Dominican Republic. Results showed that tourism employment constituted an opportunity source for women to gain both economic and social independence and generated tension between women and men in the negotiation of new gender roles and identities.

Within the tourism context, sexual orientation has also been the subject of research. For instance, Poria (2006) investigated the experiences of gay men and lesbians in hotels who deemed as important feeling accepted and welcome when their sexual orientation is known as well as desire to be treated in the same fashion as heterosexuals. Hotel staff behavior, hotel attributes, and its environment were considered critical elements of hotel experience. Hughes \& Deutsch (2010) examined holidays of older gay men finding holiday requirements as similar to those of other older people but with the extra dimension of gay-friendliness as well as identifying opportunities for tour operators and destinations to develop products positioned more adequately for this market segment.

Tourism with the purpose of leisure and visiting friends and relatives was found to be related 
with the family lifecycle (Collins \& Tisdell, 2002). Furthermore, these authors stated that whereas lifecycle cross-sectional tourism functions might shift overtime, they were likely to remain relatively stable in their overall features, i.e. the age groups at which they peak as well as the relative position of the age groups were unlikely to see substantial variations.

Taking the age variable into account, millennials are one of the largest groups to be targeted by tourism firms. Rita et al. (2019) compared the travel motivations of Millennials from US and UK by ratings, rankings and perceptual structures of push/pull factors. Findings revealed their homogeneity in push travel motivations and destination activity preferences. "To relax" and "to escape from the ordinary" constituted the most important motivational factors whereas "to try local food" and "to go sightseeing" were the most attractive destination activities.

Dann (2001) studied senior tourism in the UK by assessing how this type of tourism was being promoted. More specifically, a comparative content analysis of the brochures of six of the main tour operators at that time was made in order to ascertain the main messages being transmitted, also including sole targeting versus principal targeting of this age-based market segment, the vocabulary of motive that was employed, among other issues. Further, Fleischer \& Pizam (2002) surveyed senior citizens in Israel to identify factors that influence their decision to take holidays for differing time lengths and found that their tourism motivation was a function of income and health, but their trip duration changed with age.

Later, Chen \& Schumaker (2014) analyzed the psychological characteristics and travel behavior of American senior leisure tourists, comparing three generations coined as the silent generation, the lucky few, and the baby boomers. Findings supported the applicability of life cycle theory to the senior travel market and suggested that marketing programs geared toward the senior market needed to be updated. Moreover, a study exploring the factors determining the tourism attractiveness of a seniors-friendly destination was conducted by Lee \& King (2019) who found that their essential components included barrier-free public transportation and accommodation facilities, barrier-free facilities along customized travel routes, and variety of seniors-only accommodation and public transport options. Another recent study was performed by Oliveira et al. (2018) to identify the determinants of quality of life and well-being of senior residential tourists living in Portugal. Empirical findings showed that quality of neighborhoods explained 
senior residential tourists' aesthetic value, and also suggested that local social relationships matter to them as well as beauty, security and safety.

Recently, the field of religion and tourism was analyzed by Collins-Kreiner (2020) covering progress according to disciplines, authors, journals, and religions, performing a meta-analysis, presenting insights and current trends. Another very interesting study involving the religiontourism nexus was reported by Battour et al. (2017) who found 'Religion' significantly moderating the relationship between tourism motivations and tourist satisfaction.

Concerned with the disabled, who account nowadays for about one billion citizens, Benjamin et al. (2020) explored how people with disabilities were represented in tourism promotional materials, namely tourism brochures in the US Southeast, and identified these perpetuating a homogenous gaze targeting mainly non-disabled audiences.

The important role to be played by tourism development also in reducing regional income inequality was studied by Li et al. (2016) with empirical findings indicating that tourism development contributed significantly to the reduction of regional inequality in China, with domestic tourism making a greater contribution when compared to international tourism. The impact of tourism on income inequality in developing economies was also addressed by researchers. For example, Alam \& Paramati (2016). The long-run elasticities on squared tourism revenue confirmed that if the current level of tourism becomes double then it will significantly reduce the income inequality in developing economies. In turn, Raza \& Shah (2017) examined the relationship between tourism and the income inequality in top tourist arrival countries with results confirming that tourism has a positive effect on income inequality in full and the regionwise sample, also concluding that if the examined countries increased their tourism revenue this would help them reducing income inequality.

\section{Data and Methods}

With the goal of studying how national DMOs promoted their respective countries in terms of inclusiveness, their promotion materials were the subject of research analysis. Since 
investigating all national DMOs' promotion materials or even their website content would be a daunting task, a decision was made to focus on the English brochures available at the websites of nine European DMOs. The choice of European countries was made not because of personal affinity but due to the fact that Europe is clearly the largest continent in terms of tourism flows and generated revenue. In reality, according to the World Tourism Organization, whereas Europe topped USD 570 billion and 710 million arrivals, Asia/Pacific, the second region ranked in the world, achieved USD 435 billion and 348 millions arrivals (UNWTO, 2019). Besides the requirement of having brochures written in English, the sample selection criteria took in consideration two other parameters: (1) geographic representation, and (2) each country's positioning in the 2019 Inclusiveness Index ranking (Menendian et al., 2019). Based on these criteria, the three top-ranking positioned countries from each European region, were selected:

- Northern Europe: Sweden $\left(2^{\text {nd }}\right)$, Ireland $\left(5^{\text {th }}\right)$, United Kingdom (UK) $\left(6^{\text {th }}\right)$

- Eastern Europe: Czech Republic $\left(19^{\text {th }}\right)$, Poland $\left(37^{\text {th }}\right)$, Hungary $\left(52^{\text {th }}\right)$

- Southern Europe: Portugal $\left(4^{\text {th }}\right)$, Spain $\left(59^{\text {th }}\right)$, Greece $\left(64^{\text {th }}\right)$

As tourism brochures are a distinctive advertisement medium in the tourism industry, where both textual and visual components play an essential part in conveying the sales argument (Brito and Pratas, 2015), both components were analyzed. To do so, Data Science methods were employed (see: Rita et al., 2018), in particular Text Mining (Guerreiro \& Rita, 2019) and Image Mining. Although many constitute examples of the application in tourism research of Topic Modeling (Calheiros et al., 2017), Sentiment Analysis (Moro et al., 2019), Text Classification, Text Clustering, among other Text Mining techniques (Li et al., 2019; Oliveira et al., 2019), the same is not valid for Image Mining which is a novel approach. Effectively, the Scopus database showed that only one publication matched the query " "image mining" AND tourism", a publication from Lin et al. (2019). Search with "image classification" AND tourism showed that Image Classification, an Image Mining technique that automatically labels and classifies images, was present in 58 publications which is a much higher number, but still very low compared to Text Mining related techniques. The combination of Text Mining and Image Mining, as recognized by Lin et al. (2019), makes it possible to analyze the similarity between textual and 
visual content, and, most importantly, allows to understand if there are dissimilarities between explicit and implicit content, respectively.

\subsection{Text Mining}

As shown in Table 1, 109 brochures were collected from the national DMOs' websites, covering a wide range of destination information. That range went from generic destination and regional information to family holidays, music tourism, medical tourism, cultural tourism, meetings and congresses, religious tourism, city breaks, food, golf, among other themes. All the brochures were presented in PDF file format. The process started by analyzing the textual component of the brochures, using the Python programming language with several additional libraries, namely: the Natural Language Toolkit (NLTK) (Bird et al., 2009), Beautiful soup (Richardson, 2007), PyPDF2 (Phaseit, Inc., n.d.), and other standard Python packages such as Pandas, Numpy, Matplotlib, and Seaborn. A preprocessing transformation was applied to each PDF:

1. Extraction of the text by page;

2. Tokenization of the text into sentences, i.e., the splitting of the text into sentences;

3. Per sentence:

a. Removal of HTML markup code;

b. Removal of punctuation, numbers, line breaks, and special ASCII characters;

c. Normalization (conversion of all text to lower case);

4. Tokenization of the sentences into words, i.e., the splitting of sentences into words;

5. Per word:

a. Removal of stopwords (words that were common in a language or lexicon, such as "a" or "the" and that did not bring significant meaning to a text);

b. Lemmatization of words (reducing the word to the dictionary form of a word "lemma");

6. Reconstruction of sentences with the words' transformations.

The text preprocessing resulted, as shown in Table 1, in the identification of a total of 625,882 words. 
Table 1. Summary Statistics of Collected Data

\begin{tabular}{|c|c|c|c|c|c|c|}
\hline Country & Website & \#Brochures & \#Words & $\begin{array}{r}\text { Ratio } \\
\text { words } \\
\text { per } \\
\text { brochure }\end{array}$ & \#Images & $\begin{array}{r}\text { Ratio } \\
\text { images } \\
\text { per } \\
\text { brochure }\end{array}$ \\
\hline Czech Republic & https://www.czechtourism.com & 17 & 112,797 & $6,635.1$ & 326 & 19.2 \\
\hline Greece & http://www.visitgreece.gr & 8 & 17,610 & $2,201.3$ & 486 & 60.8 \\
\hline Hungary & https://wowhungary.com & 7 & 33,568 & $3,051.6$ & 447 & 40.6 \\
\hline Ireland & https://www.ireland.com & 11 & 91,347 & $10,149.7$ & 2,187 & 243.0 \\
\hline Poland & https://www.poland.travel & 4 & 14,141 & $3,535.3$ & 277 & 69.3 \\
\hline Portugal & https://www.visitportugal.com & 26 & 121,197 & $4,661.4$ & 2,924 & 112.5 \\
\hline Spain & https://www.spain.info & 6 & 9,894 & $1,649.0$ & 338 & 56.3 \\
\hline Sweden & https://visitsweden.com & 15 & 77,115 & $5,141.0$ & 2,938 & 195.9 \\
\hline UK & https://www.visitbritain.com & 13 & 148,213 & $11,401.0$ & 1,252 & 96.3 \\
\hline & Total & 109 & 625,882 & $5,742.0$ & 11,175 & 102.6 \\
\hline
\end{tabular}

The next step in terms of analysis was to build a list of terms related to the dimensions of inclusion addressed by Menendian et al. (2019): race, gender, age, religion, ethnicity, income inequality, political representation, and sexual orientation. Building this list started by the analysis of the top frequent n-grams in the text. N-grams are a contiguous sequence of $n$ terms from a given sample of text. unigrams, bigrams, and trigrams were analyzed. Figure 1 and Figure 2 show the top 20 unigrams and bigrams, respectively.

Figure 1. Top 20 Frequent Unigrams

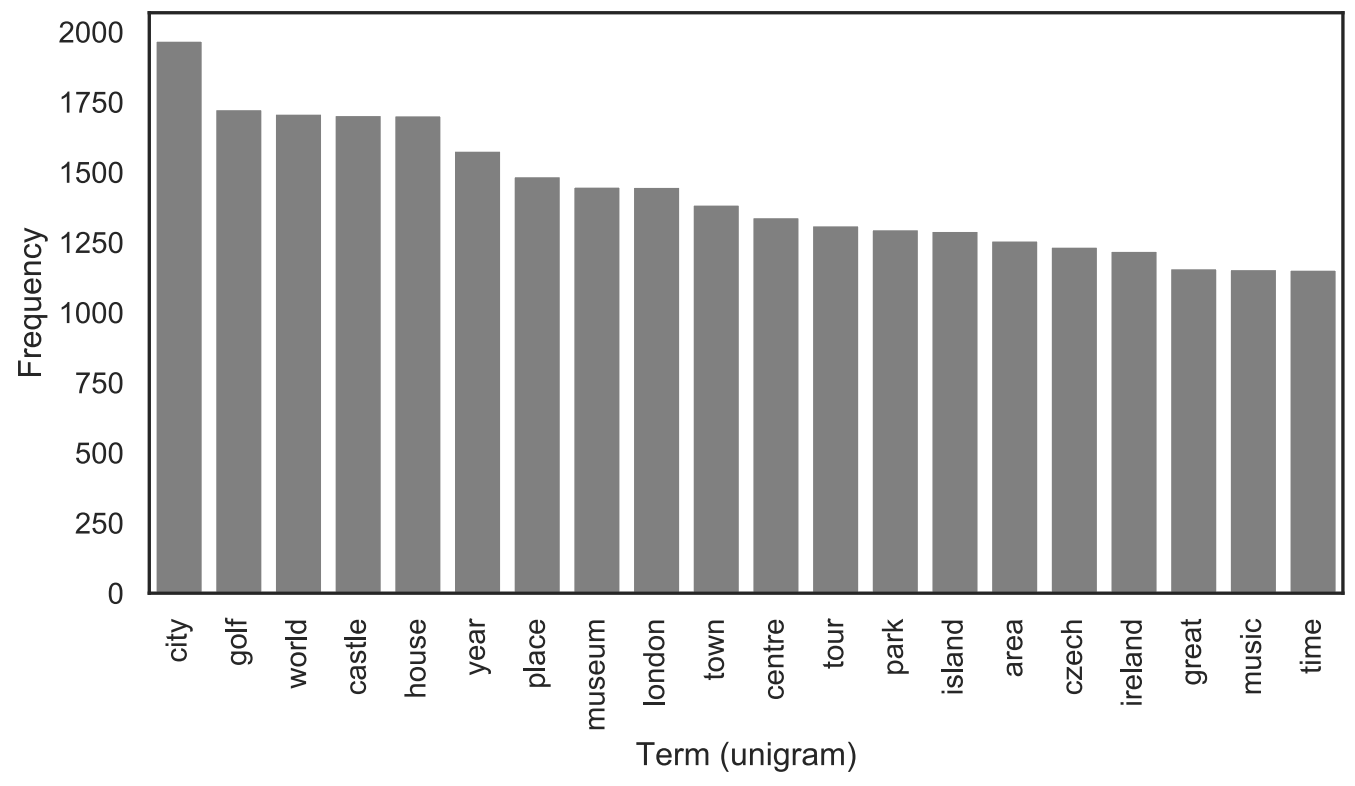


Figure 2. Top 20 Frequent Bigrams

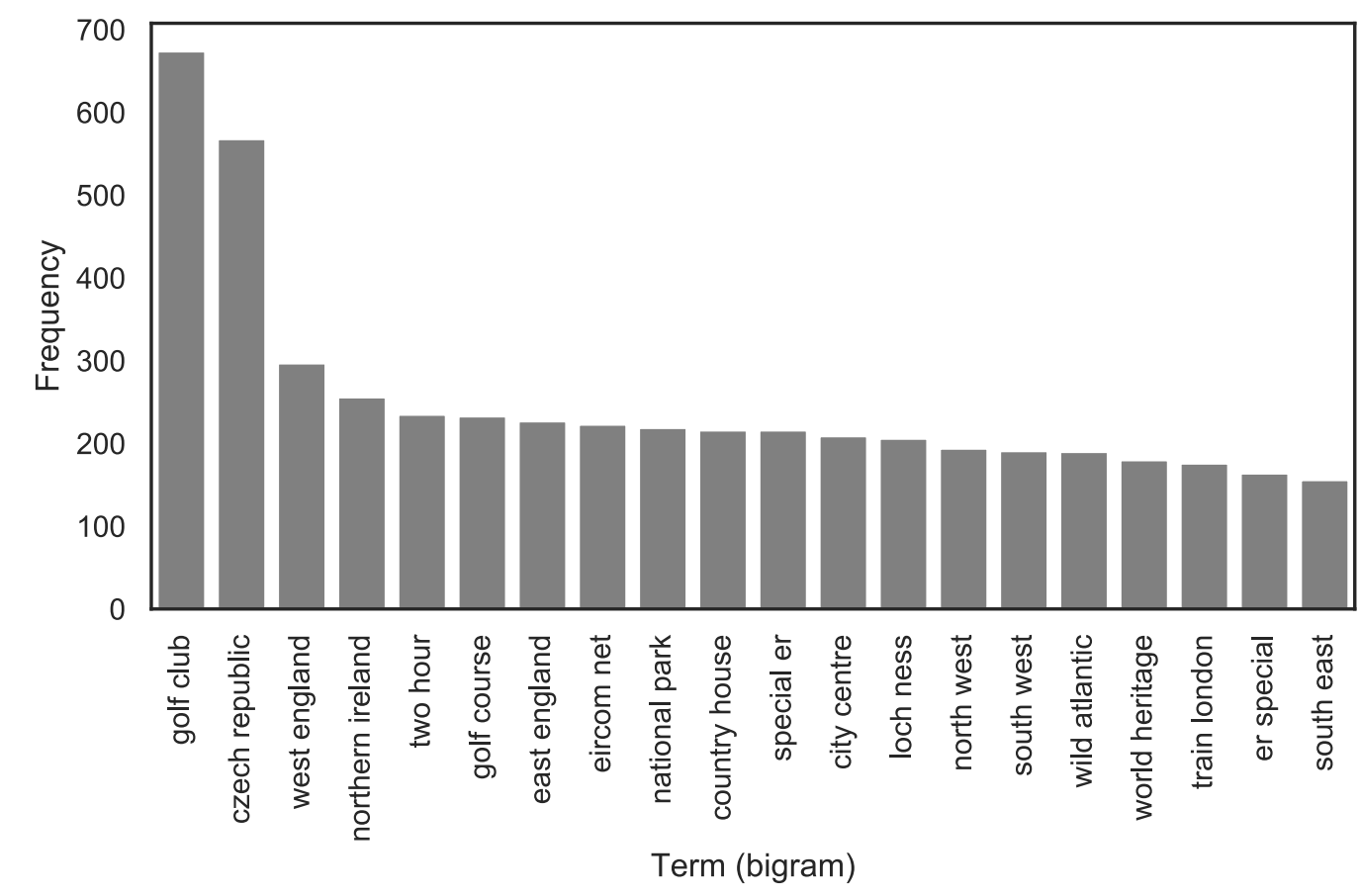

Text Annotation was also carried out, where part-of-speech tagging was performed to identify words' morpho-syntactic categories (nouns, verbs, adjectives, among others). An example of this analysis, the top 20 frequent nouns, can be seen in Figure 3. Having into consideration the terms employed in the 2019 Inclusiveness Index ranking (Menendian et al., 2019) and the top frequent terms found in the brochures' textual component, the following terms were included in the list: accessible, acumen, alternative, anyone, anti-discrimination, asylum, authorization, bias, corruption, discrimination, disable, disability, diversity, ethnic, ethnicity, everyone, inclusion, inclusiveness, international, immigrant, intolerant, gay, gender, handicap, lgb, lgbt, lgbtq, nationality, multicultural, perception, permission, race, religion, selective, sex, sexual orientation, skin, tolerant, unfair, visa, wheel chair, wheelchair, and xenophobia. 
Figure 3. Top 20 Frequent Nouns

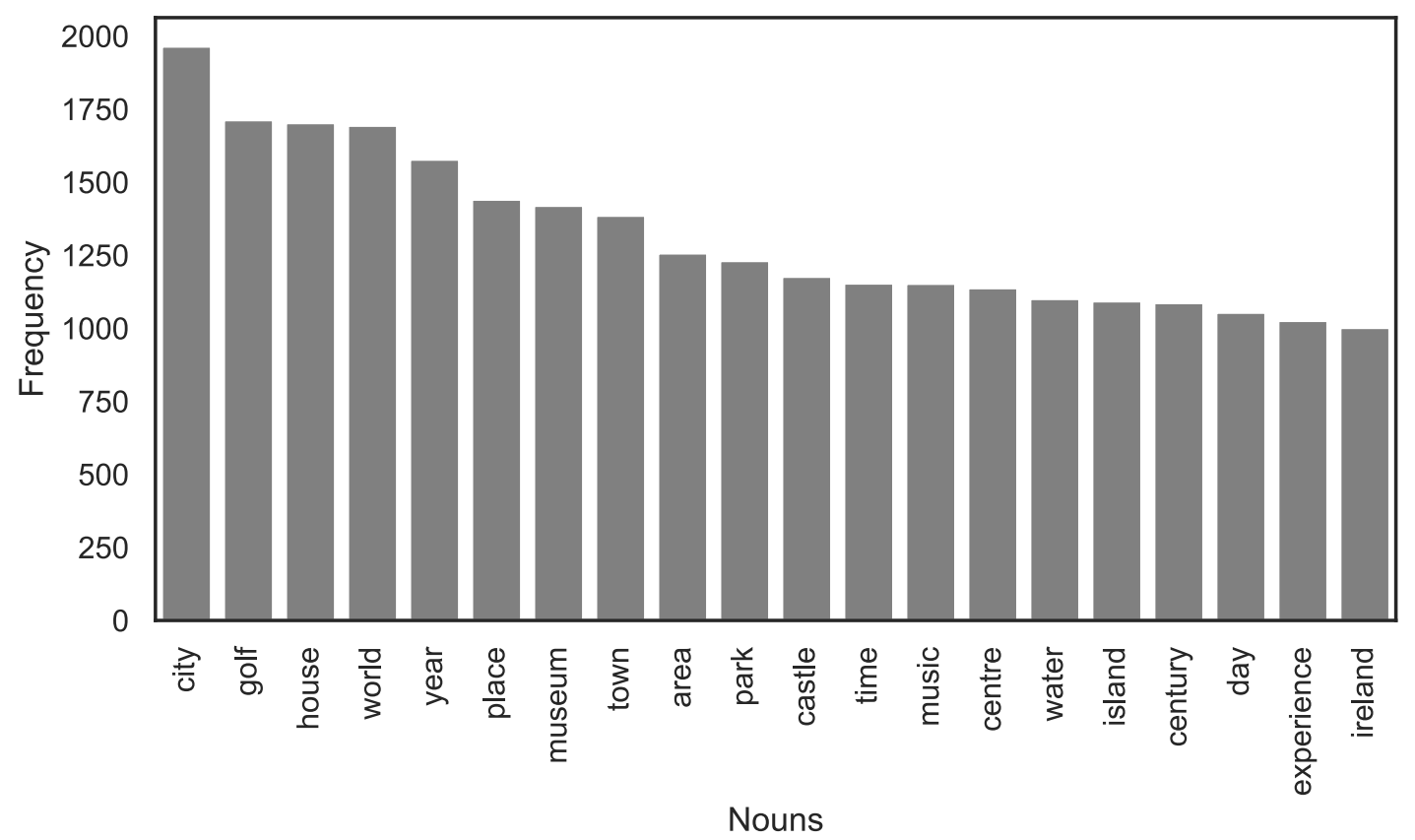

Then, all the sentences that included any of the terms of the search list were identified. This identification allowed not only to understand which terms were most employed, but mainly to focus attention on these sentences and understand if the use of each term was related to any form of either inclusion or discrimination.

\subsection{Image Mining}

As previously done when addressing the textual component, in the analysis of the image component of brochures the Python programming language was also used. The first step of this analysis was to identify the images themselves. With the help of the Python package Fitz (Kastman, n.d.), PNG image files were extracted from all images included in the brochures. As shown in Table 1, that resulted in a total of 11,175 images. These images were then classified using the "Computer vision" service from Microsoft's Cognitive Services API (Application Programming Interface). Microsoft's Cognitive Services are a set of Machine Learning algorithms developed by Microsoft to enable developers to easily incorporate Artificial Intelligence into their applications (Microsoft, 2017). The "computer vision" service can "read" an image and recognize over 10,000 objects and textual information in 25 languages. For each image processed, the "Computer vision" service returns a JSON object with, among other data: image metadata (e.g., height and width), list of objects with an associated confidence level in 
percentage, a list of tags (based on the objects present in the image), a caption (constructed based on the tags found in the image), and a confidence level of the caption. When people are present in the image and faces are visible, gender and age are also estimated.

After classifying all images, the total of images by tags and also the caption were analyzed. However, since computer vision algorithms have a high number of false positives, after comparing a sample of images classification results with the actual images, a decision was made to only analyze images with a confidence level of the caption being superior to $90 \%$.

\section{Results and Discussion}

In the 2019 Inclusiveness Index ranking (Menendian et al., 2019), northern European countries tended to occupy higher positions. Portugal was the one clear exception, occupying the $4^{\text {th }}$ place in the ranking, behind Netherlands, Sweden, and Norway. The $5^{\text {th }}$ and $6^{\text {th }}$ in the ranking, as described earlier, were Ireland and the UK. Curiously, the first pattern identified was related to summary statistics and the positioning of countries in the ranking. Although there was no significant statistical relationship between the average number of words and the average number of images per brochure $\left(R^{2}=0.2448\right)$, as clearly visible in Figure 4, altogether higher positioned countries tended to have more words per brochure and noticeably also more images per brochure than lower positioned countries. This finding led us to consider the hypothesis that brochures with longer texts and a higher number of images could reflect the country's attitude towards inclusion. Brochures with longer texts and a higher number of images could reflect the country's DMO effort to show diversity, which does not mean the same as inclusion but nevertheless is highly associated with it (Roberson, 2006). 
Figure 4. Average Words per Brochure vs. Average Images per Brochure

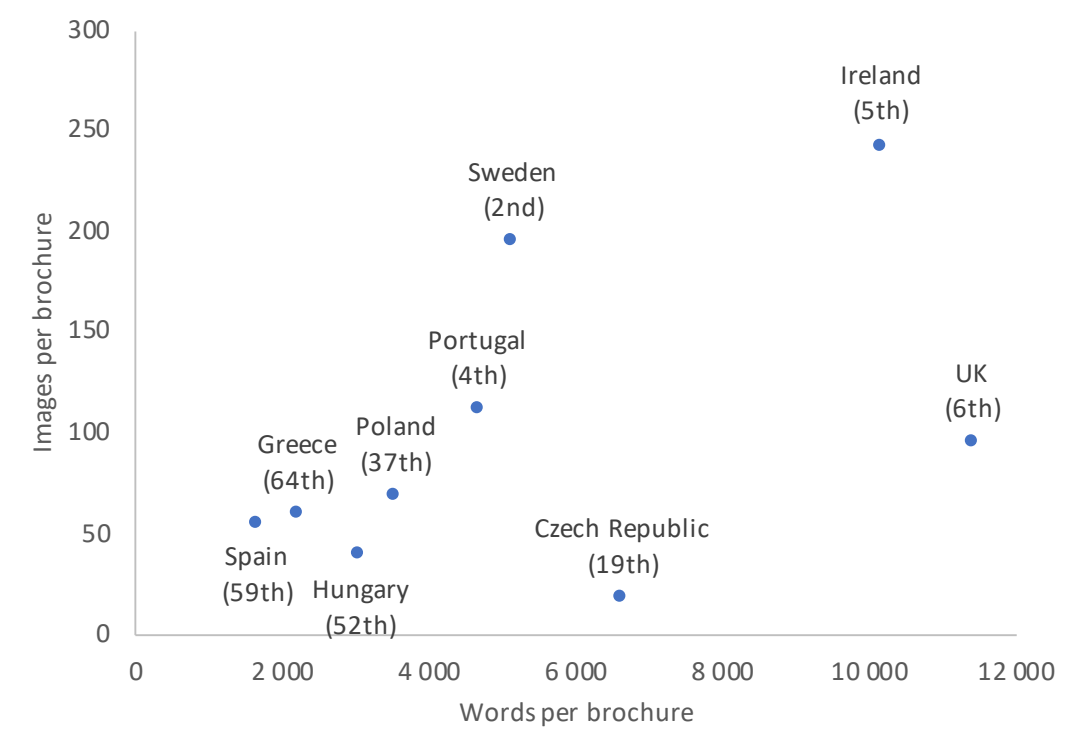

The text analysis frequencies, as presented in Table 2, also showed that the number of distinct terms employed in the four better-positioned countries in the 2019 Inclusiveness Index ranking (Menendian et al., 2019) was well above the remaining countries. Tourism diversity offers could explain that. In fact, some countries could have more tourism products to offer than others, thus the high number of distinct terms. Notwithstanding, it is possible to see that this is not the case, as countries like Spain or Greece are known for their diverse tourism offer.

Furthermore, as shown in Table 2, from the total 38,492 extracted sentences, 1,107 (2.9\%), included terms from the search list. However, the reading of these sentences revealed, as expected, that the use of the search terms was, in most cases, not related to inclusion, nor even diversity. Sometimes words, although having the same spelling and pronunciation, have different meanings (homonyms). That was the case for example with the term "race":

- "Poland is dominated by lowlands, which promotes cross-country skiing and ski trips. In March, thousands of professionals and amateurs participate in an international RACE called Bieg Piastów” (Poland).

- “Sweden's biggest obstacle course RACE is coming to Kalmar for the first time" (Sweden) 
Similar examples were found for the terms "alternative", "accessible", "visa", "handicap", among others. In other cases, the use of the term in the sentence was not explicitly or implicitly related to inclusion. For example, the use of the "international" term: "The Czech spa industry is characterised by world-class experts and by high quality of treatment guaranteed by INTERNATIONAL certifications..." (Czech Republic). Other terms such as "anyone" or "everyone" in the sense that anyone and everyone is welcomed in the country. However, in some cases the search list terms were indeed used to specifically highlight inclusion. Mentions related to the inclusion of disabled people were found in the brochures of five countries: Czech Republic, Ireland, Portugal, Sweden, and the UK. Concerning gender, a brochure from Ireland gave the example of a beach where men and women were split into different sides of the same beach, but that is not the case anymore. A UK brochure mentioned two interpretations of Shakespeare's plays where the male-female five pairs of actors played multi-assigned roles, regardless of gender. Sexual orientation inclusion was also addressed explicitly in brochures from Ireland, Spain, and with a high number of mentions in brochures from the UK, advertising gay/LGB parades, festivals, or friendly places.

Portugal, Ireland, UK, and Greece advertised multicultural/ethnic events and places as attractions to visit those countries. In terms of religion, Portugal and Greece not only promoted religious tourism, but they also used the coexistence and tolerance of the different religions as a promoting tool. Portugal and Ireland explicitly used their tolerance as a form of welcoming everyone: “...you will find a religious but TOLERANT people...” (Portugal), “... an open minded, independent, welcoming, TOLERANT people..." (Ireland). On the other hand, Portugal and Ireland, as well as the Czech Republic, Hungary, and Sweden mentioned the requirement of visas might apply for tourists from some countries, which can be seen as a signal contrary to inclusion based on the nationality of visitors.

All national DMOs advertised their conditions for the practice of multiple sports and sport events. Golf, as seen in Figure 1 and Figure 2, was the highest mentioned sport. Indeed, golf was mentioned in the brochures of seven of the nine studied countries. Only Hungary and Poland had no mentions of golf. Of course, golf is a tourist product, and as such it must be promoted. However, from the inclusion promotion point-of-view, golf is seen as a wealthier sport, and golf 
promotion may be considered the promotion of income inequality. The same could be said about promoting luxury living and shopping, as promoted by the Czech Republic, Spain, and the UK.

Table 2. Words and Sentences Frequencies Analysis

\begin{tabular}{|l|r|r|r|r|}
\hline Country & $\begin{array}{r}\text { Distinct } \\
\text { words }\end{array}$ & $\begin{array}{r}\text { Total } \\
\text { sentences }\end{array}$ & $\begin{array}{r}\text { Sentences } \\
\text { with terms } \\
\text { from the } \\
\text { search list }\end{array}$ & $\begin{array}{r}\text { Sentences with } \\
\text { terms from the } \\
\text { search list (\%) }\end{array}$ \\
\hline Czech Republic & 2,051 & 5,408 & 230 & $4.3 \%$ \\
\hline Greece & 637 & 1,259 & 62 & $4.9 \%$ \\
\hline Hungary & 1,089 & 2,188 & 78 & $3.6 \%$ \\
\hline Ireland & 2,189 & 4,841 & 142 & $2.9 \%$ \\
\hline Poland & 739 & 1,185 & 24 & $2.0 \%$ \\
\hline Portugal & 2,486 & 6,587 & 162 & $2.5 \%$ \\
\hline Spain & 374 & 573 & 13 & $2.3 \%$ \\
\hline Sweden & 2,947 & 6,693 & 101 & $1.5 \%$ \\
\hline UK & 3,697 & 9,758 & 295 & $3.0 \%$ \\
\hline & & 38,492 & 1,107 & $2.9 \%$ \\
\hline
\end{tabular}

Image Mining exposed a different perspective from the text component of the brochures. The more subjective nature of images could explain that difference, but it also signifies that the level of effort to promote inclusion in the textual component was not the same as the level effort put in the creation of the visual component. From the 806 "objects" (tags) found in images, 20 were identified that could be related to inclusion or diversity (see Table 3). The images' classification with those tags were then analyzed and, in many cases, the images were reviewed. The analysis showed that in terms of race, the vast majority of people in images were Caucasians. This finding is not unexpected since the vast majority of people in the studied countries are Caucasian.

However, other minorities are living in these countries, which were not represented proportionally in the images. For example, from the 233 images with the tag "children", only two had a non-Caucasian child. The only country whose DMO used images with people from different races to generic promoting the country was the UK. The Czech Republic had a photo of a wedding with an Asian couple (man and woman) which seems to be related to attract Asians for wedding tourism, and Spain that used photos with people from different races to attract foreign Spanish students and meeting/conference events. Although the frequency of the tags suggested the opposite, the visualization of the images suggests there is an equilibrium in the use of gender images. However, in terms of age, there seemed to be an exclusion of older people in all images. Most countries tended to use photos with young people, families with children, and 
middle-aged adults. Only Portugal, Ireland, and Sweden seemed to present images with senior people deliberately. Images with families did not take into consideration the actual definition of families, with single-parent families or same-gender parents. All family's images were of a Caucasian man and woman couple and their children. Moreover, there were many sports-related images, but none with adapted sports, which could be interpreted as a form of exclusion. Also, disabled people were only present in two images. The two images were related to the promotion of medical tourism. Portugal made use of graffiti and street art images to promote the multicultural environment in the nation.

Table 3. Inclusion related Tags identified in Images per Country

\begin{tabular}{|l|r|r|r|r|r|r|r|r|r|r|}
\hline \multicolumn{1}{|c|}{ Tag } & $\begin{array}{c}\text { Czech } \\
\text { Republic }\end{array}$ & Greece & Hungary & Ireland & Poland & Portugal & Spain & Sweden & UK & Total \\
\hline Black & 51 & 29 & 46 & 313 & 33 & 177 & 25 & 227 & 73 & 974 \\
\hline Boy & 66 & 7 & 13 & 68 & 13 & 68 & 8 & 159 & 38 & 440 \\
\hline Child & 37 & 2 & 8 & 33 & 3 & 27 & 3 & 91 & 29 & 233 \\
\hline Church & 168 & 22 & 68 & 52 & 30 & 180 & 27 & 42 & 75 & 664 \\
\hline Couple & 9 & 2 & 2 & 22 & 4 & 18 & 2 & 10 & 6 & 75 \\
\hline Crowd & 20 & 13 & 10 & 61 & 2 & 57 & 23 & 55 & 75 & 316 \\
\hline Dancer & 1 & 2 & 1 & 0 & 1 & 1 & 2 & 2 & 5 & 15 \\
\hline Family & 1 & 0 & 0 & 2 & 0 & 0 & 0 & 1 & 0 & 4 \\
\hline Female & 1 & 1 & 0 & 0 & 0 & 1 & 0 & 8 & 2 & 13 \\
\hline Girl & 72 & 5 & 16 & 91 & 21 & 45 & 15 & 147 & 48 & 460 \\
\hline Graffiti & 3 & 0 & 0 & 2 & 1 & 9 & 0 & 3 & 5 & 23 \\
\hline Lady & 5 & 0 & 0 & 10 & 0 & 2 & 2 & 12 & 1 & 32 \\
\hline Male & 0 & 0 & 0 & 0 & 0 & 0 & 0 & 1 & 0 & 1 \\
\hline Man & 546 & 257 & 234 & 1,147 & 160 & 1,394 & 182 & 1,270 & 612 & 5,802 \\
\hline Mother & 0 & 0 & 0 & 0 & 0 & 0 & 0 & 1 & 0 & 1 \\
\hline People & 382 & 203 & 155 & 752 & 107 & 1,000 & 133 & 873 & 423 & 4,028 \\
\hline Person & 187 & 33 & 45 & 338 & 28 & 151 & 67 & 409 & 178 & 1,436 \\
\hline Wedding & 7 & 2 & 2 & 6 & 3 & 7 & 0 & 12 & 4 & 43 \\
\hline Woman & 279 & 72 & 86 & 520 & 58 & 402 & 92 & 686 & 283 & 2,478 \\
\hline Young & 206 & 28 & 44 & 357 & 38 & 262 & 53 & 502 & 182 & 1,672 \\
\hline Total & 2,041 & 678 & 730 & 3,774 & 502 & 3,801 & 634 & 4,511 & 2,039 & 18,710 \\
\hline
\end{tabular}

\section{Conclusion}

This study's findings answer positively to the initially proposed research question. In fact, results show that countries' attitudes towards inclusion, as revealed in the 2019 Inclusiveness 
ranking were aligned with what the countries' DMOs were promoting, especially in the case of those highly-ranked but there was a difference between their textual (explicit content) and visual (implicit content) components, since image mining showed a different perspective from the text component of the brochures.

The collected information about each destination ranged from general destination and regional information to more focused one about family holidays, medical tourism, cultural tourism, music tourism, religious tourism, meetings and congresses, city breaks, food, and golf.

Forty-three different terms were identified in this research associated with inclusive tourism, more specifically: accessible, acumen, alternative, anyone, anti-discrimination, asylum, authorization, bias, corruption, discrimination, disable, disability, diversity, ethnic, ethnicity, everyone, inclusion, inclusiveness, international, immigrant, intolerant, gay, gender, handicap, lgb, lgbt, lgbtq, nationality, multicultural, perception, permission, race, religion, selective, sex, sexual orientation, skin, tolerant, unfair, visa, wheel chair, wheelchair, and xenophobia.

The number of distinct terms used in the four better-positioned countries in the 2019 Inclusiveness Index ranking was found to be well above the remaining five countries. Effectively, brochures with longer texts and a higher number of images reflected each country's attitude towards inclusion via its DMO's effort to show diversity.

The automatic extraction of texts and images from PDF files enables researchers to access high volumes of data and conduct research with advanced methods and techniques. Nevertheless, the automatic extraction of texts and images, particularly of text, rely on algorithms that although being very accurate do not present accuracy of 100\%. Therefore, although an inspection in a random sample has not shown any missing texts, there is the possibility of that occurring. However, even if that happened, the percentage of missing text should be so small that it would not influence global results.

Text Mining and Image Mining are highly effective methods in the analysis of large volumes of textual and image data, but both have limitations related to the probabilistic nature of some of the Artificial Intelligence algorithms. This means that some classifications done by the algorithms could not be correct (e.g., the identification of nouns in Text Mining or the identification of 
objects in Image Mining). Of course, a human can also fail or disagree with other humans in some classifications but today the error in the classifications done by these algorithms tends to be bigger than the error achieved by humans. However, at the speed these algorithms are being improved, and at the speed new algorithms are appearing, it is expected that a similar analysis made in the near future could present improved results.

\section{References}

Alam, M. S., \& Paramati, S. R. (2016). The impact of tourism on income inequality in developing economies: Does Kuznets curve hypothesis exist?. Annals of Tourism Research, 61, 111-126.

Bakker, M. (2019). A conceptual framework for identifying the binding constraints to tourismdriven inclusive growth. Tourism Planning \& Development, 16(5), 575-590.

Battour, M., Ismail, M. N., Battor, M., \& Awais, M. (2017). Islamic tourism: an empirical examination of travel motivation and satisfaction in Malaysia. Current Issues in Tourism, 20(1), 50-67.

Benjamin, S., Bottone, E., \& Lee, M. (2020). Beyond accessibility: exploring the representation of people with disabilities in tourism promotional materials. Journal of Sustainable Tourism, 119.

Biddulph, R., \& Scheyvens, R. (2018). Introducing inclusive tourism. Tourism Geographies, $20(4), 583-588$.

Bird, S., Klein, E. and Loper, E. (2009), Natural Language Processing with Python, 1st ed., O’Reilly, Beijing; Cambridge [Mass.].

Brito, P.Q. and Pratas, J. (2015), “Tourism brochures: Linking message strategies, tactics and brand destination attributes", Tourism Management, Vol. 48, pp. 123-138.

Calheiros, A. C., Moro, S., \& Rita, P. (2017). Sentiment classification of consumer-generated 
online reviews using topic modeling. Journal of Hospitality Marketing \& Management, 26(7), 675-693.

Chen, S. C., \& Shoemaker, S. (2014). Age and cohort effects: The American senior tourism market. Annals of Tourism Research, 48, 58-75.

Collins, H. (2003). Discrimination, equality and social inclusion. The Modern Law Review, $66(1), 16-43$.

Collins, D., \& Tisdell, C. (2002). Age-related lifecycles: Purpose variations. Annals of Tourism Research, 29(3), 801-818.

Collins-Kreiner, N. (2020). Religion and tourism: A diverse and fragmented field in need of a holistic agenda. Annals of Tourism Research, 82 (May).

Dann, G. M. (2001). Targeting seniors through the language of tourism. Journal of Hospitality \& Leisure Marketing, 8(3-4), 5-35.

Duffy, L. N., Kline, C. S., Mowatt, R. A., \& Chancellor, H. C. (2015). Women in tourism: Shifting gender ideology in the DR. Annals of Tourism Research, 52, 72-86.

Figueroa-Domecq, C., Pritchard, A., Segovia-Pérez, M., Morgan, N., \& Villacé-Molinero, T. (2015). Tourism gender research: A critical accounting. Annals of Tourism Research, 52, 87-103.

Fleischer, A., \& Pizam, A. (2002). Tourism constraints among Israeli seniors. Annals of Tourism Research, 29(1), 106-123.

Garau-Vadell, J. B., Gutierrez-Taño, D., \& Diaz-Armas, R. (2018). Economic crisis and residents' perception of the impacts of tourism in mass tourism destinations. Journal of Destination Marketing \& Management, 7, 68-75.

Garrod, B., \& Fyall, A. (2017). Collaborative destination marketing at the local level: Benefits bundling and the changing role of the local tourism association. Current Issues in Tourism, 20(7), 668-690.

Guerreiro, J., \& Rita, P. (2019). How to predict explicit recommendations in online reviews 
using text mining and sentiment analysis. Journal of Hospitality and Tourism Management. 43 (June), 269-272.

Hitchcock, M. (1999). Tourism and ethnicity: Situational perspectives. International Journal of Tourism Research, 1(1), 17-32.

Hughes, H. L., \& Deutsch, R. (2010). Holidays of older gay men: Age or sexual orientation as decisive factors?. Tourism Management, 31(4), 454-463.

Jamison, D. (1999). Tourism and ethnicity: The brotherhood of coconuts. Annals of Tourism Research, 26(4), 944-967.

Kastman, E. (n.d.). Fitz 0.0.1.Dev2 ～: Fitz: Workflow Mangement for Neuroimaging Data., Python, , available at: http://github.com/kastman/fitz (accessed 12 June 2020).

Krymkowski, D. H., Manning, R. E., \& Valliere, W. A. (2014). Race, ethnicity, and visitation to national parks in the United States: Tests of the marginality, discrimination, and subculture hypotheses with national-level survey data. Journal of Outdoor Recreation and Tourism, 7, 3543.

Lee, C. F., \& King, B. (2019). Determinants of attractiveness for a seniors-friendly destination: a hierarchical approach. Current Issues in Tourism, 22(1), 71-90.

Li, H., Chen, J. L., Li, G., \& Goh, C. (2016). Tourism and regional income inequality: Evidence from China. Annals of Tourism Research, 58, 81-99.

Li, Q., Li, S., Zhang, S., Hu, J. and Hu, J. (2019), “A review of text corpus-based tourism big data mining", Applied Sciences (Switzerland), Vol. 9 No. 16, available at:https://doi.org/10.3390/app9163300.

Lin, L., Gang, R., Hong, T. and Yang, S.-B. (2019), "Exploring Simultaneous Presentation in Online Restaurant Reviews : An Analysis of Textual and Visual Content", Asia Pacific Journal of Information Systems, Vol. 29 No. 2, pp. 181-202.

Marasco, A., Buonincontri, P., van Niekerk, M., Orlowski, M., \& Okumus, F. (2018). Exploring 
the role of next-generation virtual technologies in destination marketing. Journal of Destination Marketing \& Management, 9, 138-148.

Menendian, S., Elsheikh, E. and Gambhir, S. (2019), 2019 Inclusiveness Index: Measuring Global Inclusion and Marginality, Othering \& Belonging Institute, Berkeley, CA, available at: berkeley.edu/inclusivenessindex.

Microsoft. (2017), “Cognitive Services APIs: Vision”, Windows Developer Blog, 13 February, available at: https://blogs.windows.com/windowsdeveloper/2017/02/13/cognitive-services-apisvision/ (accessed 13 June 2020).

Moro, S., Rita, P., Esmerado, J., \& Oliveira, C. (2019). Unfolding the drivers for sentiments generated by Airbnb Experiences. International Journal of Culture, Tourism and Hospitality Research. 13 (4), 430-442

Muler Gonzalez, V., Coromina, L. and Galí, N. (2018), "Overtourism: residents' perceptions of tourism impact as an indicator of resident social carrying capacity - case study of a Spanish heritage town", Tourism Review, Vol. 73 No. 3, pp. 277-296.

Okumus, B., Xiang, Y., \& Hutchinson, J. (2018). Local cuisines and destination marketing: Cases of three cities in Shandong, China. Asia Pacific Journal of Tourism Research, 23(6), 584599.

Oliveira, C., Brochado, A., \& Correia, A. (2018). Seniors in international residential tourism: looking for quality of life. Anatolia, 29(1), 11-23.

Oliveira, C., Brochado, A., Moro, S., \& Rita, P. (2019). Consumer perception of tourist experience through online reviews. Worldwide Hospitality and Tourism Themes. 11 (6), 696717.

Phaseit, Inc. (n.d.). PyPDF2: PDF Toolkit, Python, , available at: http://mstamy2.github.com/PyPDF2 (accessed 11 June 2020).

Poria, Y. (2006). Assessing gay men and lesbian women's hotel experiences: An exploratory study of sexual orientation in the travel industry. Journal of Travel Research, 44(3), 327-334. 
Raza, S. A., \& Shah, N. (2017). Tourism growth and income inequality: does Kuznets Curve hypothesis exist in top tourist arrival countries. Asia Pacific Journal of Tourism Research, 22(8), 874-884.

Richardson, L. (2007), "Beautiful Soup Documentation - Beautiful Soup 4.9.0 documentation", available at: https://www.crummy.com/software/BeautifulSoup/bs4/doc/ (accessed 11 June 2020).

Rita, P., Brochado, A., \& Dimova, L. (2019). Millennials' travel motivations and desired activities within destinations: A comparative study of the US and the UK. Current Issues in Tourism, 22(16), 2034-2050.

Rita, P., Rita, N., \& Oliveira, C. (2018). Data science for hospitality and tourism. Worldwide Hospitality and Tourism Themes. 10 (6), 717-725

Roberson, Q.M. (2006), "Disentangling the Meanings of Diversity and Inclusion in Organizations", Group \& Organization Management, SAGE Publications Inc, Vol. 31 No. 2, pp. 212-236.

Scheyvens, R. (2002). Tourism for development: Empowering communities. Harlow: Pearson Education.

Scheyvens, R \& Biddulph, R (2018) Inclusive tourism development, Tourism Geographies, 20(4),589-609.

UNDP (2015) 2030 Agenda for Sustainable Development, United Nations, New York.

UNWTO (2019), “International Tourism Highlights: 2019 Edition” World Tourism

Organization, available at: https://www.e-unwto.org/doi/pdf/10.18111/9789284421152 (accessed 11 June 2020).

UNWTO (2020) World Tourism Barometer No 18, World Tourism Organization. 